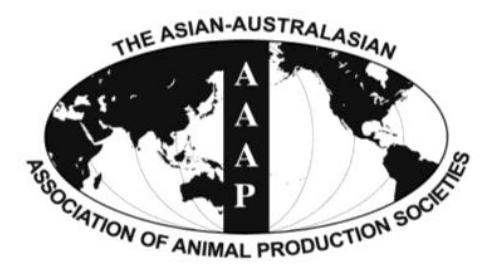

Asian Australas. J. Anim. Sci.

Vol. 26, No. 7 : 935-944 July 2013

http://dx.doi.org/10.5713/ajas.2012.12636

www.ajas.info

pISSN $1011-2367$ elSSN 1976-5517

\title{
The Effects of Thyme and Cinnamon Essential Oils on Performance, Rumen Fermentation and Blood Metabolites in Holstein Calves Consuming High Concentrate Diet
}

\author{
A. R. Vakili, B. Khorrami*, M. Danesh Mesgaran, and E. Parand \\ Department of Animal Science, Ferdowsi University of Mashhad, Mashhad, Iran
}

\begin{abstract}
Essential oils have been shown to favorably effect in vitro ruminal fermentation, but there are few in vivo studies that have examined animal responses. The objective of this study was to evaluate the effects of thyme (THY) and cinnamon (CIN) essential oils on feed intake, growth performance, ruminal fermentation and blood metabolites in feedlot calves fed high-concentrate diets. Twelve growing Holstein calves $(213 \pm 17 \mathrm{~kg}$ initial BW) were used in a completely randomized design and received their respective dietary treatments for $45 \mathrm{~d}$. Treatments were: 1-control (no additive), 2-THY (5 g/d/calf) and 3-CIN (5 g/d/calf). Calves were fed $a d$ libitum diets consisting of $15 \%$ forage and $85 \%$ concentrate, and adapted to the finishing diet by gradually increasing the concentrate ratio with feeding a series of transition diets 5 wk before the experiment started. Supplementation of THY or CIN did not affect DMI and ADG, and feed efficiency was similar between treatment groups. There were no effects of additives on ruminal $\mathrm{pH}$ and rumen concentrations of ammonia nitrogen and total VFA; whereas molar proportion of acetate and ratio of acetate to propionate decreased, and the molar proportion of propionate increased with THY and CIN supplementation. Rumen molar concentration of butyrate was significantly increased by adding CIN compared to control; but no change was observed with THY compared with control group. No effects of THY, or CIN were observed on valerate, isobutyrate or isovalerate proportions. Plasma concentrations of glucose, cholesterol, triglyceride, urea-N, $\beta$-hydroxybutyrate, alanine aminotransferase and aspartate aminotransferase were not changed by feeding THY or CIN. Results from this study suggest that supplementing a feedlot finishing diet with THY or CIN essential oil might be useful as ruminal fermentation modifiers in beef production systems, but has minor impacts on blood metabolites. (Key Words: Thyme Oil, Cinnamon Oil, Rumen Fermentation, Blood Metabolites, Growth Performance, Beef Cattle)
\end{abstract}

\section{INTRODUCTION}

In order to increase performance and feed efficiency, beef cattle are fed diets containing high quantities of cereal grains; but highly fermentable substances in diets can decrease ruminal $\mathrm{pH}$ and may increase the risk of acidosis and bloat (Nocek, 1997). Antibiotics have been used in beef diets successfully to improve the efficiency of nutrient utilization and to impede or reduce the incidence of ruminal acidosis and bloat (Bergen and Bates, 1984). However, the use of antibiotics as feed additives in animal feeds due to the appearance of residues in milk and meat and their effects on human health is banned in the European Union (European Union, 2003); accordingly, use of these compounds has become increasingly controversial. In the

\footnotetext{
* Corresponding Author: Behzad. Khorrami. Tel: +98-511-879 6845, Fax: +98-511-8796845, E-mail: behzad.khorami@gmail.com Submitted Nov. 13, 2012; Accepted Jan. 31, 2013; Revised Feb. 14, 2013
}

last few years, there has been an increasing attention in the potential of plant extracts such as essential oils (EO) as alternatives for feed antibiotics and growth promoters in ruminant nutrition.

Essential oils are volatile aromatic compounds present in many plants that are generally extracted by steam and/or water distillation. Chemically, EO are a blend of secondary metabolites commonly composed of terpenoids and phenylpropanoids (Calsamiglia et al., 2007). These compounds have been shown to favorably manipulate ruminal fermentation and improve nutrient utilization in ruminants (Hristov et al., 1999). Moreover, EO have been evaluated for their antimicrobial activity and they are more recently being investigated as rumen modifiers in ruminants (Wallace, 2005). Recent comprehensive reviews published on EO and their active components (Calsamiglia et al., 2007; Benchaar et al., 2008) have indicated that some EO can promote rumen microbial fermentation and approvingly alter rumen metabolism. However, most researches 
conducted to date on EO have been laboratory based (i.e., in vitro) and of short-term nature (Cardozo et al., 2005; Busquet et al., 2006; Hristov et al., 2008). There are very limited in vivo studies that have evaluated effectiveness of EO on performance, rumen fermentation, and metabolism in beef cattle fed high concentrate diets.

Two of EO with high potential for use in the diets of ruminants are thyme oil (THY) and cinnamon oil (CIN). Results from in vitro (Castillejos et al., 2006; Martinez et al., 2006; Fraser et al., 2007) and in vivo (Cardozo et al., 2006; Benchaar et al., 2006a;b; Yang et al., 2010a;b) studies on effects of THY and CIN or their main active components have been contradictory; and more research is needed to understand their effects on rumen fermentation and metabolism in cattle. Antimicrobial effect of thymol (a phenolic monoterpene and main active compound of THY) is attributing to the disruption of the plasma membrane of bacteria and a reduction in the uptake of glucose (Calsamiglia et al., 2007; Benchaar et al., 2008); and the antimicrobial impact of cinnamaldehyde (a non-phenolic phenylpropene and main active compound of CIN) is suggested to arise through its carbonyl group interaction with proteins in the periplasm and inactivating microbial enzymes (Nikaido, 1994; Burt, 2004). However, antimicrobial activity of $\mathrm{EO}$ is dependent on ruminal $\mathrm{pH}$, with a more pronounced effect at a lower ruminal $\mathrm{pH}$ (Calsamiglia et al., 2007); whereas low pH could increase the influence of some active compounds of EO due to conformational changes in their structure and the higher sensibility of rumen bacteria to these compounds (Skandamis and Nychas, 2000). To the best of our knowledge, no research has synchronously compared the effects of THY and CIN in beef production systems. Also most studies have been carried out with dairy cattle rumen fluid and diets, and generalizing results to beef cattle consuming high levels of concentrate can be misleading, because effects of EO have been indicated that can be highly dependent on diet and the ruminal $\mathrm{pH}$ (Cardozo et al., 2005; Castillejos et al., 2005).

The objectives of this study were to evaluate effects of THY and CIN on feed intake, growth performance, ruminal fermentation characteristics and blood metabolites in growing Holstein calves fed high-concentrate diets.

\section{MATERIAL AND METHODS}

\section{Animals, experimental design and treatments}

Twelve growing Holstein bull calves with an average initial BW of $213 \pm 17 \mathrm{~kg}$ were used in a completely randomized design. At the start of the experiment, calves were weighed and randomly assigned to 1 of 3 treatments: 1-control (CON; basal total mixed ration with no additive), 2-control diet with THY $(5 \mathrm{~g} / \mathrm{d} /$ calf $)$ and 3 -control diet with
CIN $(5 \mathrm{~g} / \mathrm{d} / \mathrm{calf})$.

\section{Preparation of essential oils}

Thyme (Thymus vulgaris) and cinnamon (Cinnamomum cassia) plants were collected from semi-arid climate of Iran and then EO content of these plants (leaves and bark, respectively) were extracted with hydro distillation method using Clevenger type apparatus. In brief, $70 \mathrm{~g}$ ground samples of each plant were put in a round bottom flask and $1000 \mathrm{ml}$ distilled water was added and then subjected to hydro distillation for $3 \mathrm{~h}$. The recovered oil was transferred into glass vials and stored at $4^{\circ} \mathrm{C}$ in a lab refrigerator.

\section{Diet and animal management}

The concentrate portion of diet consisted of $400 \mathrm{~g} / \mathrm{kg}$ barley grain, $400 \mathrm{~g} / \mathrm{kg}$ corn grain, $129 \mathrm{~g} / \mathrm{kg}$ cottonseed meal, $59 \mathrm{~g} / \mathrm{kg}$ soybean meal and $12 \mathrm{~g} / \mathrm{kg}$ supplement on a DM basis. The forage portion of diet consisted of dry alfalfa hay. The basal diet was composed of $15 \%$ alfalfa hay and $85 \%$ concentrate, and the ingredients and nutrient composition of the basal diet (DM basis) is given in Table 1. Diets were fed as total mixed rations (TMR) and formulated according to NRC (1996) recommendations. The concentrate portion of the basal diet were mixed and bagged off site, and sufficient concentrate mixes were prepared for the entire study. The experimental diets were offered twice (08:00 and 16:00 h) daily for ad libitum intake (10\% refusals) with one-half of the daily feed allotment offered at each feeding. The calves were adapted to the finishing diet over a period of $5 \mathrm{wk}$

Table 1. Ingredients and nutrient composition of the basal diet (DM basis)

\begin{tabular}{lr}
\hline Items & \% of dietary DM \\
\hline Ingredient composition & 15.00 \\
Alfalfa hay & 34.00 \\
Barley grain, ground & 34.00 \\
Corn grain, ground & 5.00 \\
Soybean meal & 11.00 \\
Cottonseed meal & 0.30 \\
Salt & 0.50 \\
Calcium carbonate & 0.20 \\
Mineral-vitamin premix & \\
Nutrient composition & 93.10 \\
DM & 15.51 \\
CP & 2.80 \\
Ether extract & 21.53 \\
NDF & 12.30 \\
ADF & 6.40 \\
Ash & 0.53 \\
Calcium & 0.35 \\
Phosphorus
\end{tabular}

${ }^{1}$ Contained: 20 g/kg Mg, 50 g/kg K, 30 g/kg Zn, 20 g/kg Mn, 30 g/kg Fe, $3 \mathrm{~g} / \mathrm{kg} \mathrm{Cu}, 0.01 \mathrm{~g} / \mathrm{kg} \mathrm{Se}, 0.1 \mathrm{~g} / \mathrm{kg} \mathrm{Co}, 0.1 \mathrm{~g} / \mathrm{kg} \mathrm{I}, 500 \mathrm{IU} / \mathrm{g}$ of vitamin A, $100 \mathrm{IU} / \mathrm{g}$ of vitamin $\mathrm{D}$, and $1 \mathrm{IU} / \mathrm{g}$ of vitamin $\mathrm{E}$. 
before the beginning of the experiment by feeding a series of transition diets, each fed for $7 \mathrm{~d}$. The transition diets were composed of gradually increasing proportion of concentrate to alfalfa hay $(45: 55,55: 45,65: 35,75: 25$ and $85: 15$, respectively) in TMR on DM basis. Therefore, the calves received a final transition diet consisting of $85 \%$ concentrate and $15 \%$ alfalfa hay as the experimental diet 1 wk before the experiment started. Animals were fed the finishing diets for $45 \mathrm{~d}$. The THY and CIN additives were mixed with a small amount of concentrate and once daily top dressed onto the TMR before feeding to ensure that calves would consume the full amount offered. Amounts of feed offered and refused were recorded daily for each animal throughout the trial. Body weight was measured at the beginning and the end of experiment. The calves were housed in individual tie stalls on mattresses bedded with straw in pens $(2 \mathrm{~m} \times 1.5 \mathrm{~m})$ equipped with a water bowl. The pens were located in a covered barn. Each animal had free access to water at all times.

\section{Measurements, sample collection and analyses}

The feed intake was determined daily for each animal. Average daily gain was calculated for throughout the trial. Feed efficiency was calculated as the ratio between ADG and DMI.

Ruminal fluid was collected from animals at the end of the experiment ( $3 \mathrm{~h}$ after the morning feeding) via the esophagus using an electrical vacuum pump and a lubricated rubber tube. Ruminal fluid contents were monitored visually to ensure they were not polluted with saliva and then squeezed through four layers of cheesecloth. Rumen $\mathrm{pH}$ was measured immediately after sampling with a portable $\mathrm{pH}$ meter (Metrohm 744, Herisau, Switzerland). A volume of $10 \mathrm{ml}$ of the filtrated ruminal fluid was mixed with $10 \mathrm{ml}$ of $0.2 \mathrm{~N} \mathrm{HCl}$ and or with $2 \mathrm{ml}$ of $25 \%$ (wt/vol) metaphosphoric acid for $\mathrm{NH}_{3}-\mathrm{N}$ and VFA analyses, respectively. All samples were stored frozen at $-20^{\circ} \mathrm{C}$ for subsequent analyses. The ruminal fluid concentration of $\mathrm{NH}_{3}-\mathrm{N}$ was determined using distillation method (Kjeltec Auto Analyzer, Model 1030, Tecator Co., Sweden). The concentrations of ruminal VFA were measured by gas chromatography (YL6100 GC, Young Lin Instrument Co.,
Anyang, South Korea) equipped with a 50-m (0.32 mm ID) silica-fused column (CP-Wax Chrompack Capillary Column, Varian, Palo Alto, CA, USA). Helium was used as carrier gas and oven initial and final temperatures were 55 and $195^{\circ} \mathrm{C}$, respectively, and detector and injector temperatures were set at $250^{\circ} \mathrm{C}$. Crotonic acid (trans-2butenoic acid) was used as the internal standard.

Blood samples were collected from the jugular vein at the end of the trial ( $3 \mathrm{~h}$ after the morning feeding) by heparinized syringe. Samples were centrifuged at 3,500 $\times \mathrm{g}$ for $15 \mathrm{~min}$ at $4^{\circ} \mathrm{C}$, and collected plasma was immediately transported to the laboratory and frozen at $-20^{\circ} \mathrm{C}$ until analyzed. Plasma concentrations of glucose, urea-N, betahydroxybutyric acid (BHBA), triglyceride, cholesterol, aspartate aminotransferase (AST) and alanine aminotransferase (ALT) were determined using an autoanalyzer (Alcyon 300i Abbott, USA).

\section{Statistical analysis}

All data were statistically analyzed according to a completely randomized design using the general linear models (GLM) procedure of SAS software (Version 9.2). Significant differences between means of treatments were assessed by the Duncan's test, and the differences among treatments were declared significant at $\mathrm{p}<0.05$.

\section{RESULTS}

\section{Feed intake and performance}

Dry matter intake and performance data are presented in Table 2. Initial and final BW averaged 214 and $270 \mathrm{~kg}$, respectively, and did not differ among the experimental treatments and consequently, ADG was not affected by treatments. The mean DM intake of treatments ranged from 7.8 to $8.1 \mathrm{~kg} / \mathrm{d}$ and was similar for calves fed CON and those consuming diets supplemented with additives. Similarly, feed efficiency, expressed as gain: feed ratio (ADG to DMI ratio), was similar between treatment groups.

\section{Ruminal fermentation characteristics}

Mean of $\mathrm{pH}$, concentration of $\mathrm{NH}_{3}-\mathrm{N}$, total VFA concentration and proportions of individual VFA are shown

Table 2. Effects of thyme and cinnamon essential oils supplementation on performance in growing calves

\begin{tabular}{|c|c|c|c|c|c|}
\hline \multirow{2}{*}{ Items } & \multicolumn{3}{|c|}{ Treatments $^{1}$} & \multirow{2}{*}{ SEM } & \multirow{2}{*}{ p-value } \\
\hline & $\mathrm{CON}$ & THY & CIN & & \\
\hline Initial BW (kg) & 212.5 & 214.2 & 215.0 & 9.24 & 0.98 \\
\hline Final BW (kg) & 266.5 & 273.1 & 271.7 & 8.67 & 0.85 \\
\hline DMI (kg/d) & 8.0 & 8.1 & 7.8 & 0.19 & 0.47 \\
\hline $\operatorname{ADG}(\mathrm{kg} / \mathrm{d})$ & 1.19 & 1.31 & 1.26 & 0.039 & 0.15 \\
\hline $\mathrm{G}: \mathrm{F}^{2}$ & 0.151 & 0.162 & 0.160 & 0.0034 & 0.14 \\
\hline
\end{tabular}

${ }^{1}$ Treatments are including: CON; basal diet, THY; basal diet supplemented with thyme oil (5 g/calf daily), CIN; basal diet supplemented with cinnamon oil ( $5 \mathrm{~g} /$ calf daily).

${ }^{2}$ Gain: feed, calculated as total BW gain divided by total feed intake (DM basis). 
Table 3. Effects of thyme and cinnamon essential oils supplementation on rumen fermentation characteristics in growing calves

\begin{tabular}{|c|c|c|c|c|c|}
\hline \multirow{2}{*}{ Items } & \multicolumn{3}{|c|}{ Treatments $^{1}$} & \multirow{2}{*}{ SEM } & \multirow{2}{*}{ p-value } \\
\hline & $\mathrm{CON}$ & THY & CIN & & \\
\hline$\overline{\mathrm{pH}}$ & 5.98 & 5.94 & 5.87 & 0.091 & 0.69 \\
\hline $\mathrm{NH}_{3}-\mathrm{N}(\mathrm{mg} / \mathrm{dl})$ & 15.9 & 15.8 & 15.7 & 0.93 & 0.98 \\
\hline Total VFA (Mm) & 112.2 & 111.5 & 109.9 & 1.64 & 0.62 \\
\hline \multicolumn{6}{|c|}{ VFA (mol/100 mol) } \\
\hline Acetate & $58.8^{\mathrm{a}}$ & $52.9^{\mathrm{b}}$ & $53.5^{\mathrm{b}}$ & 1.39 & 0.02 \\
\hline Propionate & $24.7^{\mathrm{b}}$ & $29.6^{\mathrm{a}}$ & $28.1^{\mathrm{a}}$ & 0.99 & 0.01 \\
\hline Butyrate & $12.6^{\mathrm{b}}$ & $13.4^{\mathrm{ab}}$ & $14.4^{\mathrm{a}}$ & 0.41 & 0.03 \\
\hline Valerate & 1.58 & 1.62 & 1.66 & 0.144 & 0.93 \\
\hline Isobutyrate & 0.97 & 1.02 & 0.94 & 0.089 & 0.82 \\
\hline Isovalerate & 1.26 & 1.30 & 1.28 & 0.162 & 0.98 \\
\hline $\mathrm{A}: \mathrm{P}^{2}$ & $2.39^{\mathrm{a}}$ & $1.80^{\mathrm{b}}$ & $1.92^{\mathrm{b}}$ & 0.120 & 0.01 \\
\hline
\end{tabular}

Means in the same row with different letters $(a, b)$ are significantly different $(\mathrm{p}<0.05)$.

${ }^{1}$ Treatments are including: CON; basal diet, THY; basal diet supplemented with thyme oil ( $5 \mathrm{~g} / \mathrm{calf}$ daily), CIN; basal diet supplemented with cinnamon oil (5 g/calf daily).

${ }^{2}$ Acetate to propionate ratio.

in Table 3. Mean ruminal $\mathrm{pH}$ of treatments ranged from 5.87 to 5.98 , but was not significantly different among treatments. Ruminal fluid concentration of $\mathrm{NH}_{3}-\mathrm{N}$ was not affected by EO supplementation. The mean concentration of total VFA in experimental treatments ranged from 109 to $112 \mathrm{mM}$ and was similar in all dietary treatments. Conversely, proportions of acetate, propionate and butyrate were influenced by treatments. Supplementation of THY and CIN decreased $(p<0.05)$ rumen molar proportion of acetate and increased $(\mathrm{p}<0.05)$ molar proportion of propionate compared with CON treatment. Consequently, the acetate to propionate ratio declined $(\mathrm{p}<0.05)$ after addition of EO. Proportion of butyrate was increased ( $\mathrm{p}<0.05$ ) by adding CIN compared to $\mathrm{CON}$; whereas no change was observed by THY supplementation. Dietary treatments did not effect on valerate and branched-chain VFA (isobutyrate and isovalerate) proportions.

\section{Blood metabolites}

Table 4 represents the effects of the nutritional treatments on blood metabolites. Concentrations of plasma glucose, urea-N, triglyceride and total cholesterol were not affected by additive treatments. Plasma BHBA concentration was not altered by the EO supplementation. Also, there were no significant differences in the plasma concentrations of ALT and AST among treatments.

\section{DISCUSSION}

\section{Feed intake and performance}

There are little information on the effect of THY and CIN on DMI and growth performance in feedlot cattle, but main active components of THY and CIN were evaluated in some of different studies and their results were inconsistent. Cardozo et al. (2006) observed no change in DMI when dietary supplementing with a mixture of $600 \mathrm{mg} / \mathrm{d}$ of cinnamaldehyde and $300 \mathrm{mg} / \mathrm{d}$ of eugenol in beef heifers fed a high concentrate diet. In a study with growing lambs, Chaves et al. (2008b) found that addition of carvacrol or cinnamaldehyde $(200 \mathrm{mg} / \mathrm{kg}$ of dietary DM) had no effect on DMI in the barley- or corn-concentrate based diets. Similar results were observed by Benchaar et al. (2006a)

Table 4. Effects of thyme and cinnamon essential oils supplementation on blood metabolites in growing calves

\begin{tabular}{|c|c|c|c|c|c|}
\hline \multirow{2}{*}{ Items } & \multicolumn{3}{|c|}{ Treatments $^{1}$} & \multirow{2}{*}{ SEM } & \multirow{2}{*}{ p-value } \\
\hline & $\mathrm{CON}$ & THY & CIN & & \\
\hline$\overline{\text { Glucose }(\mathrm{mg} / \mathrm{dl})}$ & 75.5 & 80.5 & 81.5 & 4.33 & 0.59 \\
\hline Urea N (mg/dl) & 14.5 & 14.7 & 14.2 & 1.25 & 0.96 \\
\hline Triglyceride (mg/dl) & 15.5 & 16.2 & 15.7 & 0.58 & 0.67 \\
\hline Total cholesterol (mg/dl) & 61.7 & 70.3 & 64.5 & 5.29 & 0.53 \\
\hline $\operatorname{BHBA}(\mathrm{mM})^{2}$ & 0.24 & 0.30 & 0.35 & 0.038 & 0.19 \\
\hline $\operatorname{ALT}(\mathrm{U} / \mathrm{L})^{3}$ & 57.7 & 62.7 & 56.7 & 4.33 & 0.59 \\
\hline $\operatorname{AST}(\mathrm{U} / \mathrm{L})^{4}$ & 63.2 & 59.5 & 55.3 & 5.95 & 0.65 \\
\hline
\end{tabular}

${ }^{1}$ Treatments are including: CON; basal diet, THY; basal diet supplemented with thyme oil (5 g/calf daily), CIN; basal diet supplemented with cinnamon oil (5 g/calf daily).

${ }^{2} \mathrm{BHBA}=\beta$-hydroxybutyrate. ${ }^{3} \mathrm{ALT}=$ Alanine aminotransferase. ${ }^{4} \mathrm{AST}=$ Aspartate aminotransferase. 
who reported no change in DMI of beef cattle fed a silage based diet supplemented with 2 or $4 \mathrm{~g} / \mathrm{d}$ of a commercial mixture of EO compounds consisting of thymol, eugenol, vanillin and limonene. Our results confirm these reports which showed that supplementing feedlot cattle with THY and CIN had no effect on DMI and performance. In contrast recently Yang et al. (2010b) reported that dietary supplementation with cinnamaldehyde increased DMI of feedlot cattle in the early wk of the fattening period, although, cinnamaldehyde had no effect on DMI after 4 wk of the experiment. Lack of effect of EO on DMI has been reported (Benchaar et al., 2007; Yang et al., 2007; Tassoul et al., 2009; Tager and Krause, 2011), but also other studies showed that EO can decrease DMI (Cardozo et al., 2006; Fandino et al., 2008). In some of studies, depression of DMI in cattle supplemented with EO might be related to palatability problems, proposing that the EO require to be encapsulated to overcome this problem (Calsamiglia et al., 2007). Although, addition of THY and CIN to diet can be detected through olfaction, they do not seem to modify feed intake in calves at the doses selected; whereas direct comparisons of DMI between THY and CIN fed beef cattle are very scarce. The effects of EO on DMI might vary with EO source, type of diet, diet interactions or adaptation of rumen microbial populations to EO (Yang et al., 2010b;c; Graci et al., 2012). Furthermore, it has been reported that DMI can be affected by a number of dietary or management factors, such as BW, animal growth stage, specific physical and chemical characteristics of diets (i.e., fiber content, particle size, amount and ruminal degradation of protein, etc.), digestion, or rumen fermentation metabolites (Allen, 2000; Yang et al., 2007;2010c). However, results from studies used main active compounds of THY and CIN in beef animals (Cardozo et al., 2006; Chaves et al., 2008b; Yang et al., 2010b); could not be attributed directly to THY and CIN; because the EO used in present study are composed of some active compounds, and have been shown that mixtures of these compounds can cause additive, synergistic or antagonistic antimicrobial properties (Benchaar et al., 2008). Generally, there have been no differences in DMI and ADG between CON and EO fed calves, and thus the feed efficiency has not been altered; our results are consistent with the finding of Benchaar et al. (2006a) and Yang et al. (2010b).

\section{Ruminal fermentation characteristics}

Varieties of results have been reported on effects of EO on ruminal $\mathrm{pH}$. The findings of the present study for ruminal $\mathrm{pH}$ were in line with previous researches in sheep (Chaves et al., 2008a;b), dairy cows (Yang et al., 2007; Kung et al., 2008; Tager and Krause., 2011), and beef cattle (Cardozo et al., 2006; Fandino et al., 2008; Meyer et al., 2009; Yang et al., 2010a;c) that found no effect of EO on
$\mathrm{pH}$. It should be noted, that although ruminal $\mathrm{pH}$ was unaffected by EO supplementation, the mean ruminal $\mathrm{pH}$ of the bull calves in this research was lower (5.87 to 5.98) compared to results (6.08 to 6.52) of Devant et al. (2007); which examined effects of plant extract supplementation in young Holstein bulls who consumed high concentrate diets. This may be related to the higher amount of ruminal VFA concentration of beef cattle in our experiment (109 to 112 $\mathrm{mM}$ ) in compared to mentioned study (88 to $102 \mathrm{mM}$ ); because it has been reported that there is a negative relationship between VFA concentration and $\mathrm{pH}$ in the rumen (Allen, 1997). Also, Beauchemin and McGinn (2005) reported that the higher VFA concentration of cattle fed corn grain (versus barley grain) is consistent with the lower ruminal $\mathrm{pH}$ of these cattle. Benchaar et al. (2006b;2007) reported an increase in ruminal $\mathrm{pH}$ when dairy cows received EO. Their opposing results can be partially described by the type of diets used, because there is a main difference in diets among dairy cattle study and the present beef cattle study. Results from in vitro studies indicated that the $\mathrm{pH}$ could be influenced by the dose used of EO. For instance, Evans and Martin (2000) observed that addition of $400 \mathrm{mg} / \mathrm{L}$ of thymol, increased the $\mathrm{pH}$ in 24-h in vitro batch cultures, whereas lower (i.e., 50, 100, and 200 $\mathrm{mg} / \mathrm{L})$ doses had no effect on $\mathrm{pH}$. A higher $\mathrm{pH}$ at high dose of thymol $(400 \mathrm{mg} / \mathrm{L})$ could be related by a reduction in acetate, propionate, lactate and methane concentrations, suggesting that the rumen microbial fermentation has been inhibited. Similar results have been reported by Castillejos et al. (2006) using different doses (i.e., 5, 50, 500, and $5,000 \mathrm{mg} / \mathrm{L}$ ) of some EO including eugenol, thymol, guaiacol, limonene, and vanillin; and the increased $\mathrm{pH}$ with $500 \mathrm{mg} / \mathrm{L}$ of thymol was consisted with a depression in total VFA concentration, reflecting a reduction in diet fermentability because of antimicrobial activity of thymol. In a subsequent research by the same authors, addition of different doses (i.e., 5, 50 and $500 \mathrm{mg} / \mathrm{L}$ ) of THY in the batch culture fermentation experiment by a 10:90 forage to concentrate diet decreased $\mathrm{pH}$ at all used doses; whereas the decreased $\mathrm{pH}$ was associated with an increase in total VFA concentration (Castillejos et al., 2008). These results show that the range of optimum and toxic doses in thymol is narrow and might be difficult to define optimum dose. Further, whereas THY and CIN and their main active components have been indicated to alter ruminal fermentation in vitro at high doses, their effects at high doses in vivo are not clear, and also it has been suggested that the doses of EO are need to modify rumen fermentation in vivo seem to be higher than those for in vitro experiments (Chaves et al., 2008b). Therefore, longer term in vivo trials are needed to obviously establish the effects of EO supplementation at more normal feeding doses. In our study, in accord with the lack of EO effects on DMI and total VFA 
concentration, ruminal $\mathrm{pH}$ were unaffected by EO supplementation. In addition, the differences in effects of EO supplementation on $\mathrm{pH}$ between in vitro and in vivo studies could be described in part by the capacity of rumen microbes to adapt and/or degrade EO components (Benchaar and Greathead, 2011).

Essential oils had variable impacts on ruminal $\mathrm{NH}_{3}-\mathrm{N}$ concentration in the different studies. Results from different in vitro studies showed that the effects of $\mathrm{EO}$ and their main components on rumen $\mathrm{NH}_{3}-\mathrm{N}$ concentration are dose dependent and that these compounds are more effective when used at high doses compared with at low doses. For example, Castillejos et al. (2006) evaluated the effects of increasing doses $(0,5,50,500$, and $5,000 \mathrm{mg} / \mathrm{L})$ of thymol and eugenol on rumen fermentation in a $24-\mathrm{h}$ in vitro batch culture fermentations; and reported that at the highest dose (i.e., 5,000 mg/L), these compounds decreased the ruminal concentration of $\mathrm{NH}_{3}-\mathrm{N}$, but no effects were observed at lower doses. Similarly, it has been shown that CIN and its main active component cinnamaldehyde decrease the $\mathrm{NH}_{3}$ $\mathrm{N}$ concentration at high (i.e., 3,000 mg/L) level (Busquet et al., 2006). Our results are not consistent with results of Castillejos et al. (2006) who demonstrated that all doses of THY (T. vulgaris) decreased $\mathrm{NH}_{3}-\mathrm{N}$ concentration when administrated in an in vitro batch fermentation system using high concentrate feedlot-type diets (10:90 forage to concentrate). Most of in vivo studies have been shown EO often do not influence concentration of ruminal $\mathrm{NH}_{3}-\mathrm{N}$ (Benchaar et al., 2006b;2007; Devant et al., 2007; Yang et al., 2007; Yang et al., 2010a;c) that consistent with our finding in this research. Any way results in the current trial are generally in agreement with the results of some authors (Castillejos et al., 2005; Busquet et al., 2005; Fraser et al., 2007) and disagrees with other researchers who used a commercial mixture of EO compounds (McIntosh et al., 2003; Newbold et al., 2004). Besides, the differences among these studies may be related to the experimental method used (in vivo vs in vitro). Furthermore, it has been indicated that the lack of effects of EO on nitrogen metabolism in long-term studies (i.e., in vivo) compared with short-term studies (i.e., in vitro batch culture) could be attributed to the longer exposure duration of rumen microorganisms to EO. Based on this finding, higher time of exposure may lead to adaption of rumen microbial populations to the EO, because probably some of the EO compounds are degradable by ruminal bacteria (Cardozo et al., 2004; Busquet et al., 2005). Cardozo et al. (2004) reported that the effect of different EO such as cinnamon, garlic, anise, oregano and pepper disappeared after 6 to $7 \mathrm{~d}$ incubation in dual-flow continuous culture fermenters. Accordingly, results derived from short-term in vitro batch culture could be misleading and need to be interpreted with caution.
Addition of EO or their main active components has caused either a reduction or no alteration in total VFA concentration in many of in vitro and in vivo studies evaluating effects of THY and CIN or their constituents on total and individual VFA concentrations. Busquet et al. (2006) studied effects of CIN and cinnamaldehyde on rumen fermentation in an in vitro batch culture; and results of this study showed that high doses of CIN and cinnamaldehyde reduce total VFA and branched-chain VFA (BCVFA) concentrations. However, the proportion of propionate and acetate were only increased by cinnamaldehyde and CIN, respectively. Although cinnamaldehyde is the main and most active component in CIN, may interact with other compounds exist within CIN, which can alter the results. Similar findings were reported by Castillejos et al. (2006) for thymol and eugenol using doses up to $5,000 \mathrm{mg} / \mathrm{L}$. In a subsequent trial by this group (Castillejos et al., 2008), all doses of THY (i.e., 5, 50 and $500 \mathrm{mg} / \mathrm{L}$ ) increased total VFA concentration, but did not modify the proportions of acetate, propionate, valerate, acetate to propionate ratio and BCVFA concentration. Evans and Martin (2000) noted that $400 \mathrm{mg} / \mathrm{L}$ of thymol declined the total VFA concentration and the proportion of acetate and propionate, while acetate to propionate ratio was increased. There are very few in vivo studies that investigated the effects of THY and CIN or their compounds on ruminal fermentation characteristics. A comparison among the results from this experiment with results from our in vitro experiment (unpublished) and other in vitro studies shows that the doses of THY and CIN need to prevent ruminal fermentation is higher in in vivo situation compared to in vitro studies. Recently, Yang et al. (2010a) used cinnamaldehyde at three doses $(400,800$ and 1,600 $\mathrm{mg}$ /animal per $\mathrm{d}$ ) in growing beef heifers and observed no changes in concentrations of total VFA and the molar proportions of acetate, propionate, BCVFA, and the acetate to propionate ratio. In an another study, Chaves et al. (2008b) evaluated the effects of carvacrol and cinnamaldehyde in growing lambs and reported an increase in concentration of total VFA, but molar proportions of acetate, propionate, BCVFA, and the acetate to propionate ratio were not affected. The discrepancies among results of the present study and other studies could be attributed to the differences in type, dose or chemical composition of EO, basal diet amount and composition, and experimental conditions (e.g., in vivo vs. in vitro, the length of trial) as mentioned previously. Also, source of thyme and cinnamon and the procedure of EO extracting can be additional affecting factors. Some of studies have demonstrated that some of EO and their constituents alter proportions of VFA same as monensin does (i.e., decreased acetate and increased propionate proportions), which observed in our study. The decrease in the proportion of acetate by addition 
of EO usually reported in other studies, which also observed in our experiment. This may be due to inhibition of acetate producing bacteria, which belong mostly to Gram positive ruminal bacteria and are sensitive to EO (McIntosh et al., 2003). In the rumen, Gram positive bacteria are usually acetate and butyrate producing bacteria, while Gram negative bacteria are commonly propionate producing (Stewart, 1991). Also, it may be surmised that THY and CIN suppress the growth of rumen cellylolytic bacteria, which are generally acetate-, but not propionate-producers (Wallace et al., 1994), although cellylolytic bacteria populations were not determined in this study. Results of the study of Jahani-Azizabadi et al. (2011), indicated EO obtained from some medicinal plants originating semi-arid climate have a good potential to manipulate ruminal fermentation. They suggested that the medicinal plant EO, such as THY and CIN have high inhibitory effects on in vitro rumen methane production by decreasing rumen methanogenesis activity. It is well documented (Wolin, 1975) that formation of methane is the main way of hydrogen elimination in the rumen, and the production of methane could be reduced by promoting a shift in fermentation toward propionate production. Propionate is an end-product of ruminal fermentation that needs hydrogen for production. Therefore, inhibition of methane production is usually accompanied with an increase in propionate production, and there is a good negative correlation between propionate production and methanogenesis activity (Wolin, 1975). This correlation could be described as competitive pathways for metabolic hydrogen use in the rumen (Moss et al., 2000). Although the acetate:propionate ratio in the rumen has an inverse relationship with methane, but it was shown slightly lower than propionate (Lana et al., 1998; Russell, 1998); and whereas methane was not direct correlated with acetate and butyrate production (Moss et al., 2000). Significant increase in propionate concentration by EO supplementation in this experiment may be partially related to decrease in methanoghenesis activity, although methane was not directly measured in this study. The present findings are supported by Busquet et al. (2005) using low doses of cinnamaldehyde in batch culture; and Cardozo et al. (2006) who reported that supplementation of cinnamaldehyde $(600 \mathrm{mg} / \mathrm{d})$ and eugenol $(300 \mathrm{mg} / \mathrm{d})$ decreased proportions of acetate, and increased proportions of propionate in the rumen of beef heifers fed a high concentrate diet. Therefore, changes in VFA portions may be nutritionally advantageous, because propionate is one of the main sources of metabolizable energy for ruminants and it is energetically more effective. Other in vivo researches showed no change in amounts of total or individual VFA by EO supplementation in dairy cattle (Benchaar et al., 2006b;2007; Tager and Krause, 2011) which may be a result of diet formulation as mentioned earlier. These experiments and many of in vitro studies have suggested that the effects of EO on ruminal fermentation seem to be diet- and $\mathrm{pH}$ dependent (Cardozo et al., 2005; Castillejos et al., 2005). Cardozo et al. (2005) evaluated the effects of CIN, cinnamaldehyde and eugenol in vitro using rumen fluid from beef cattle fed a 10:90 forage to concentrate diet. At $\mathrm{pH}$ 7.0, all these compounds increased acetate to propionate ratio and decreased total VFA concentration. In contrast, at $\mathrm{pH}$ 5.5, total VFA concentration increased, and the acetate: propionate ratio declined with CIN, cinnamaldehyde and eugenol supplementation. Juven et al. (1994) previously reported that the antimicrobial influence of THY and CIN enhanced as $\mathrm{pH}$ decreased from 6.5 to 5.5. The impact of $\mathrm{pH}$ on the response of THY and CIN might be related to the dissociated (hydrophilic) or undissociated (hydrophobic) status of the active molecules. In according to reports of Calsamiglia et al. (2007), only the undissociated form of the molecule can interact with the lipid bilayer of the cell membrane. Therefore, as $\mathrm{pH}$ reduces, molecules becoming undissociated and more hydrophobic, thereby interacting easier with cell membranes and exerting their antimicrobial impact (Calsamiglia et al., 2007). Moreover, sensibilities of rumen bacteria to EO appear to be increase at low $\mathrm{pH}$ (Skandamis and Nychas, 2000). Consequently, some of EO such as THY, CIN and their main active components have the potential to improve rumen VFA profile at low rumen $\mathrm{pH}$, suggesting that these changes might be profitable for beef-type production systems. In the current study no significant effects of the THY and CIN supplementation on BCVFA and ruminal $\mathrm{NH}_{3}-\mathrm{N}$ concentration, and blood urea$\mathrm{N}$ concentration were observed. Our results suggest that deamination activity in the rumen may not have been inhibited by these additives, because BCVFA are derived from deamination of amino acids in the rumen (Hino and Russell, 1985). It is also might be a result of very few proteolysis and/or deamination of amino acids, which was not measured in this study, and cannot be detected by indirect indicators such as ruminal NH3-N and BCVFA concentration or blood urea-N value. Absence of significant effects of the additive on the molar proportion of valerate was observed alike reports of some authors (Chaves et al., 2008a;b; Yang et al., 2010a;c). Also the lack of influence of THY on ruminal proportion of butyrate is agreed with the results of animal studies (Benchaar et al., 2006b;2007; Meyer et al., 2009) using a mixture of EO components supplementation including thymol, eugenol, vanillin, guaiacol, and limonene, and in vitro studies using thymol and THY (Castillejos et al., 2006;2008). In spite of some in vitro (Cardozo et al., 2004; Busquet et al., 2006; Hristov et al., 2008) and in vivo (Cardozo et al., 2006; Chaves et al., 2008a;b; Yang et al., 2010a;c) studies who reported concentration of butyrate was not influenced by CIN or its main active compounds; our results showed the significant 
increasing in butyrate proportion by CIN. This finding is similar with changes observed by EO from cinnamon leaf (Cinnamomum zeylanicum) under in vitro conditions (Fraser et al., 2007). Different impacts of THY and CIN on butyrate proportion compared with $\mathrm{CON}$ reveals that these EO may act different against rumen microbial fermentation.

\section{Blood metabolites}

Essential oils effects on blood metabolites in beef cattle have not been investigated widely. In accordance to previous researches (Devant et al., 2007; Chaves et al., 2008a; Tassoul and Shaver, 2009; Yang et al., 2010b), EO supplementation did not significantly affect blood glucose concentration. In this study, THY and CIN in diet of feedlot calves resulted in no changes in values of plasma total cholesterol and triglyceride. It has been reported that concentrations of some blood metabolites such as triglycerides can be influenced by EO supplementation via changing of feed intake (Yang et al., 2010b) and no change in triglyceride or cholesterol amounts may be contributed to lack of DMI alternation by EO. Ruminal ammonia-N in excess of microbial requirement is absorbed across the rumen wall into portal blood, and most of it is converted to urea in the liver. Therefore, synthesis of urea in the liver is performed from ammonia absorbed from the rumen; as a result, urea $\mathrm{N}$ concentration in blood is highly correlated with the rumen $\mathrm{NH}_{3}-\mathrm{N}$ concentration (Petit and Flipot, 1992; Davidson et al., 2003). Because ruminal concentration of $\mathrm{NH}_{3}-\mathrm{N}$ was not affected by EO supplementation in our study, no changes in plasma urea-N concentration has been expected. This result are in agreement with some studies with other EO (Tassoul and Shaver, 2009; Özdoğan et al., 2011) and disagrees with Yang et al. (2010a) that investigated different dosages of cinnamaldehyde in beef cattle. Although pharmacological activity of THY and CIN have been reported (Grigore et al., 2010; Jakhetia et al., 2010), and also adding of THY and CIN in the finishing diet of calves were expected to have pharmacological activity, but these compounds had no effect on hepatic enzymes. Thus these results propose that EO feeding does not seem to have a preventing influence on the function of organs associated with blood substances tested in this research.

\section{IMPLICATIONS}

The results of this study show that thyme and cinnamon essential oils have a potential to improve rumen fermentation by reducing acetate proportion and increasing the production of propionate and might be useful as ruminal fermentation modifiers in beef production systems. Our results suggest that thyme or cinnamon essential oils could be considered as suitable feed additives to manipulate rumen microbial fermentation and promising candidates to substitute antimicrobial feed additives for use in ruminant nutrition. Finally, interpreting the results from this research must be with caution; therefore, further confirmation of these results is warranted, and more in vivo studies are required to investigate the effects of variety types of thyme or cinnamon essential oils (individual or mixtures) and different supplementation levels on rumen microbial fermentation and interactions with blood metabolites to improve nutrient utilization and growth performance in beef cattle.

\section{REFERENCES}

Allen, M. S. 1997. Relationship between fermentation acid production in the rumen and the requirement for physically effective fiber. J. Dairy Sci. 80:1447-1462.

Allen, M. S. 2000. Effects of diet on short-term regulation of feed intake by lactating dairy cattle. J. Dairy Sci. 83:1598-1624.

Beauchemin, K. A., and S. M. McGinn. 2005. Methane emissions from feedlot cattle fed barley or corn diets. J. Anim. Sci. 83:653-661.

Benchaar, C., and H. Greathead. 2011. Essential oils and opportunities to mitigate enteric methane emissions from ruminants. Anim. Feed. Sci. Technol. 166-167:338-355.

Benchaar, C., J. L. Duynisveld, and E. Charmley. 2006a. Effects of monensin and increasing dose levels of a mixture of essential oil compounds on intake, digestion and growth performance of beef cattle. Can. J. Anim. Sci. 86:91-96.

Benchaar, C., H. V. Petit, R. Berthiaume, D. R. Ouellet, J. Chiquette, and P. Y. Chouinard. 2007. Effects of essential oils on digestion, ruminal fermentation, rumen microbial populations, milk production, and milk composition in dairy cows fed alfalfa silage or corn silage. J. Dairy Sci. 90:886-897.

Benchaar, C., H. V. Petit, R. Berthiaume, T. D. Whyte, and P. Y. Chouinard. 2006b. Effects of addition of essential oils and monensin premix on digestion, ruminal fermentation, milk production and milk composition in dairy cows. J. Dairy Sci. 89:4352-4364.

Benchaar, C., S. Calsamiglia, A. V. Chaves, G. R. Fraser, D. Colombatto, T. A. McAllister, and K. A. Beauchemin. 2008. A review of plant-derived essential oils in ruminant nutrition and production. Anim. Feed Sci. Technol. 145:209-228.

Bergen, W. G., and D. B. Bates. 1984. Ionophores: their effect on production efficiency and mode of action. J. Anim. Sci. 58:1465-1483.

Burt, S. 2004. Essential oils: their antibacterial properties and potential applications in foods-A review. Int. J. Food Microbiol. 94:223-253.

Busquet, M., S. Calsamiglia, A. Ferret, and C. Kamel. 2006. Plant extracts affect in vitro rumen microbial fermentation. J. Dairy Sci. 89:761-771.

Busquet, M., S. Calsamiglia, A. Ferret, P. W. Cardozo, and C. Kamel. 2005. Effects of cinnamaldehyde and garlic oil on rumen microbial fermentation in a dual flow continuous 
culture. J. Dairy Sci. 88:2508-2516.

Calsamiglia, S., M. Busquet, P. Cardozo, L. Castillejos, and A. Ferret. 2007. Essential oils as modifiers of rumen microbial fermentation: a review. J. Dairy Sci. 90:2580-2595.

Cardozo, P. W., S. Calsamiglia, A. Ferret, and C. Kamel. 2004. Effects of plant extracts on ruminal protein degradation and fermentation profiles in continuous culture. J. Anim. Sci. 82:3230-3236.

Cardozo, P. W., S. Calsamiglia, A. Ferret, and C. Kamel. 2005. Screening for the effects of natural plant extracts at different $\mathrm{pH}$ on in vitro rumen microbial fermentation of a highconcentrate diet for beef cattle. J. Anim. Sci. 83:2572-2579.

Cardozo, P. W., S. Calsamiglia, A. Ferret, and C. Kamel. 2006. Effects of alfalfa extract, anise, capsicum, and a mixture of cinnamaldehyde and eugenol on ruminal fermentation and protein degradation in beef heifers fed a high-concentrate diet. J. Anim. Sci. 84:2801-2808.

Castillejos, L., S. Calsamiglia, and A. Ferret. 2006. Effect of essential oils active compounds on rumen microbial fermentation and nutrient flow in in vitro systems. J. Dairy Sci. 89:2649-2658.

Castillejos, L., S. Calsamiglia, A. Ferret, and R. Losa. 2005. Effects of a specific blend of essential oil compounds and the type of diet on rumen microbial fermentation and nutrient flow from a continuous culture system. Anim. Feed Sci. Technol. 119:29-41.

Castillejos, L., S. Calsamiglia, J. Martín-Ereso, and H. Ter Wijlen. 2008. In vitro evaluation of effects of ten essential oils at three doses on ruminal fermentation of high concentrate feedlot-type diets. Anim. Feed Sci. Technol. 145:259-270.

Chaves, A. V., K. Stanford, M. E. R. Dugan, L. L. Gibson, T. A. McAllister, F. Van Herk, and C. Benchaar. 2008a. Effects of cinnamaldehyde, garlic and juniper berry essential oils on rumen fermentation, blood metabolites, growth performance, and carcass characteristics of growing lambs. Livest. Sci. 117:215-224.

Chaves, A. V., K. Stanford, L. L. Gibson, T. A. McAllister, and C. Benchaar. 2008b. Effects of carvacrol and cinnamaldehyde on intake, rumen fermentation, growth performance, and carcass characteristics of growing lambs. Anim. Feed Sci. Technol. 145:396-408.

Davidson, S., B. A. Hopkins, D. E. Diaz, S. M. Bolt, C. Brownie, V. Fellner, and L. W. Whitlow. 2003. Effects of amounts and degradability of dietary protein on lactation, nitrogen utilization, and excretion in early lactation Holstein cows. J. Dairy Sci. 86:1681-1689.

Devant, M., A. Anglada, and A. Bach. 2007. Effects of plant extract supplementation on rumen fermentation and metabolism in young Holstein bulls consuming high levels of concentrate. Anim. Feed Sci. Technol. 137:46-57.

Evans, J. D., and S. A. Martin. 2000. Effects of thymol on ruminal microorganisms. Curr. Microbiol. 41:336-340.

Fandĩno, I., S. Calsamiglia, A. Ferret, and M. Blanch. 2008. Anise and capsicum as alternatives to monensin to modify rumen fermentation in beef heifers fed a high concentrate diet. Anim. Feed Sci. Technol. 145:409-417.

Fraser, G. R., A. V. Chaves, Y. Wang, T. A. McAllister, K. A. Beauchemin, and C. Benchaar. 2007. Assessment of the effects of cinnamon leaf oil on rumen microbial fermentation using two continuous culture systems. J. Dairy Sci. 90:2315-2328.

Geraci, J. I., A. D. Garciarena, G. A. Gagliostro, K. A. Beauchemin, and D. Colombatto. 2012. Plant extracts containing cinnamaldehyde, eugenol and capsicum oleoresin added to feedlot cattle diets: Ruminal environment, short term intake pattern and animal performance. Anim. Feed Sci. Technol. 176:123-130.

Grigore, A., I. Paraschiv, S. Colceru-Mihul, C. Bubueanu, E. Draghichi, and M. Ichim. 2010. Chemical composition and antioxidant activity of Thymus vulgaris L. volatile oil obtained by two different methods. Romanian Biotechnol. Lett. 15:5436-5443.

Hino, T., and J. B. Russell. 1985. Effect of reducing-equivalent disposal and NADH/NAD on deamination of amino acids by intact rumen microorganisms and their cell extracts. Appl. Environ. Microbiol. 50:1368-1374.

Hristov, A. N., T. A. McAllister, F. H. Van Herk, K. J. Cheng, C. J. Newbold, and P. R. Cheeke. 1999. Effect of Yucca schidigera on ruminal fermentation and nutrient digestion in heifers. J. Anim. Sci. 77:2554-2563.

Hristov, A. N., J. K. Ropp, S. Zaman, and A. Melgar. 2008. Effects of essential oils on in vitro ruminal fermentation and ammonia release. Anim. Feed. Sci. Technol. 144:55-64.

Jahani-Azizabadi, H., M. Danesh Mesgaran, A. R. Vakili, K. Rezayazdi, and M. Hashemi. 2011. Effect of various medicinal plant essential oils obtained from semi-arid climate on rumen fermentation characteristics of a high forage diet using in vitro batch culture. Afr. J. Microbiol. Res. 5:4812-4819.

Jakhetia, V., R. Patel, P. Khatri, N. Pahuja, S. Garg, A. Pandey, and S. Sharma. 2010. Cinnamon: a parmacological review. J. Adv. Sci. Res. 1:19-23.

Juven, B. J., J. Kanner, F. Schved, and H. Weisslowicz. 1994. Factors that interact with the antibacterial action of thyme essential oil and its active constituents. J. Appl. Bacteriol. 76:626-631.

Kung-Jr, L., P. Williams, R. J. Schmidt, and W. Hu. 2008. A blend of essential plant oils used as an additive to alter silage fermentation or used as a feed additive for lactating dairy cows. J. Dairy Sci. 91:4793-4800.

Lana, R. P., J. B. Russell, and M. E. Van Amburgh. 1998. The role of $\mathrm{pH}$ in regulating methane and ammonia production. J. Anim. Sci. 76:2190-2196.

Mart'inez, S., J. Madrid, F. Hern'andez, M. D. Meg'ias, J. A. Sotomayor, and M. J. Jord'an. 2006. Effect of thyme essential oils (Thymus hyemalis and Thymus zygis) and monensin on in vitro ruminal degradation and volatile fatty acid production. J. Agric. Food Chem. 54:6598-6602.

McIntosh, F. M., P. Williams, R. Losa, R. J. Wallace, D. A. Beever, and C. J. Newbold. 2003. Effects of essential oils on ruminal microorganisms and their protein metabolism. Appl. Environ. Microbiol. 69:5011-5014.

Meyer, N. F., G. E. Erickson, T. J. Klopfenstein, M. A. Greenquist, M. K. Luebbe, P. Williams, and M. A. Engstrom. 2009. Effect of essential oils, tylosin and monensin on finishing steer performance, carcass characteristics, liver abscesses, ruminal fermentation and digestibility. J. Anim. Sci. 87:2346-2354.

Moss, A. R., J. P. Jouany, and J. Newbold. 2000. Methane production by ruminants: its contribution to global warming. Review article. Ann. Zootech. 49:231-253. 
National Research Council. 1996. Nutrient requirements of beef cattle. 7th rev. ed. Nat. Acad. Press, Washington, DC.

Newbold, C. J., F. M. McIntosh, P. Williams, R. Losa, and R. J. Wallace. 2004. Effects of a specific blend of essential oil compounds on rumen fermentation. Anim. Feed Sci. Technol. 114:105-112.

Nikaido, H. 1994. Prevention of drug access to bacterial targets: permeability barriers and active efflux. Science. 264:382-388.

Nocek, J. E. 1997. Bovine acidosis: implications on laminitis. J. Dairy Sci. 80:1005-1028.

Özdoğan, M., S. S. Önenç, and A. Önenç. 2011. Fattening performance, blood parameters and slaughter traits of Karya lambs consuming blend of essential oil compounds. Afr. J. Biotechnol. 10:6663-6669.

Petit, H. V., and P. M. Flipot. 1992. Feed utilization of beef steers fed grass as hay or silage with or without nitrogen supplementation. J. Anim. Sci. 70:876-883.

SAS Institute Inc. 2004. SAS/SAT user's guide: Version 9.2th edn. SAS Institute Inc., Cary, North Carolina.

Russell, J. B. 1998. The importance of $\mathrm{pH}$ in the regulation of ruminal acetate to propionate ratio and methane production in vitro. J. Dairy Sci. 81:3222-3230.

Skandamis, P. N., and G. J. Nychas. 2000. Development and evaluation of a model predicting the survival of Escherichia coli O157:H17 NCTC 12900 in homemade eggplant salad at various temperatures, $\mathrm{pHs}$, and oregano essential oil concentration. Appl. Environ. Microbiol. 66:1646-1653.

Stewart, C. S. 1991. The rumen bacteria. In: Rumen Microbial Metabolism and Ruminant Digestion (Ed. J. P. Jouany). INRA Editions, Paris, France. pp. 15-26.

Tager, L. R., and K. M. Krause. 2011. Effects of essential oils on rumen fermentation, milk production, and feeding behavior in lactating dairy cows. J. Dairy Sci. 94:2455-2464.
Tassoul, M. D., and R. D. Shaver. 2009. Effect of a mixture of supplemental dietary plant essential oils on performance of periparturient and early lactation dairy cows. J. Dairy Sci. 92:1734-1740.

Wallace, R. J. 2005. Symposium: Plants as animal foods: A case of catch 22? Antimicrobial properties of plant secondary metabolites. Proc. Nutr. Soc. 63:621-629.

Wallace, R. J., L. Arthaud and C. J. Newbold. 1994. Influence of Yucca schidigera extract on ruminal ammonia concentrations and ruminal microorganisms. Appl. Environ. Microbiol. 60:1762-1767.

Wolin, M. J. 1975. Interactions between the bacterial species of the rumen. In: Digestion \& Metabolism in the Ruminant (Ed. I. W. McDonald and A. C. I. Warner). University of New England Publ. Unit, Armidale, Australia. pp. 134-148.

Yang, W. Z., B. N. Ametaj, C. Benchaar, and K. A. Beauchemin. 2010a. Dose response to cinnamaldehyde supplementation in growing beef heifers: ruminal and intestinal digestion. J. Anim. Sci. 88:680-688.

Yang, W. Z., B. N. Ametaj, M. L. He, C. Benchaar, and K. A. Beauchemin. 2010b. Cinnamaldehyde in feedlot cattle diets: intake, growth performance, carcass characteristics, and blood metabolites. J. Anim. Sci. 88:1082-1092.

Yang, W. Z., C. Benchaar, B. N. Ametaj, A. V. Chaves, M. L. He, and T. A. McAllister. 2007. Effects of garlic and juniper berry essential oils on ruminal fermentation and on the site and extent of digestion in lactating cows. J. Dairy Sci. 90:56715681.

Yang, W. Z., C. Benchaar, B. N. Ametaj, and K.A. Beauchemin. 2010c. Dose response to eugenol supplementation in growing beef cattle: ruminal fermentationand intestinal digestion. Anim. Feed Sci. Technol. 158:57-64. 